\title{
Application of Geospatial Technology in the Classroom and Collaborative Learning
}

\author{
M. Iinuma, T. Matsuhashi, T. Nakamura, and H. Chiyokura
}

\begin{abstract}
Geographic Information System (GIS) has become readily available and accessible than ever before. This technology offers a new representation of the geographical space. How can educators integrate this technology in their curriculum? What is the new aspect of literacy that is unique of geospatial technology? What skills are involved in digital spatial thinking? These are questions that are still needs to be answered. In this study, we would like to introduce a case study of how Google Earth (GE) was used in a Computer Supported Collaborative Learning (CSCL) environment at a university setting. The study showed that using GE allows students to enhance the interest and understanding of social issues.
\end{abstract}

Index Terms - Geospatial technology, collaboration, higher education, curriculum.

\section{INTRODUCTION}

Open government refers to governance based on citizen participation using Information Technology such as GIS(Geographic Information System)that leads to increased information transparency of the government. In particular, one important area of open government is to support democratic decision making on both local and national government level by utilizing data available on geospatial technology such as GIS (Geographic Information System) [1] As such, making data freely available to everyone especially on GIS is a trend and a goal seen worldwide. Open data on GIS are made available to public so that geospatial data can be used to find and to solve problems in designated countries and areas throughout the world. In 2013, G8 pledged their support for the declaration to make data available and open to public for democratic use, known as the Open Data Charter, which became the global trend [1].

Digital maps and GIS technologies became readily available for citizens today and are used on everyday bases. Ability to use images and spatial technologies such as GIS critically is becoming an indispensable information literacy skill for global citizens. While open data is becoming more available, educating citizen to critically use open data is still a challenge. Furthermore, using such technologies in educational settings as well as fostering students`critical skill that pertains to the use of digital maps and open data still needs to be explored.

What is the new aspect of information literacy that is

Manuscript received October 10, 2015; revised December 17, 2015. Collaborative Learning Using Integrated Groupware: A Case Study in a Japanese Higher Education Setting.

The authors are with the Department of Media Science, Tokyo University of Technology, Tokyo, Japan (e-mail: iinuma@stf.teu.ac.jp, matsuhashi@stf.teu.ac.jp, tagiru@edu.teu.ac.jp, chiyokura@stf.teu.ac.jp). unique of geospatial technology? What skills are involved in digital spatial thinking? How can educators integrate this technology in their curriculum? These are questions that are still needs to be answered. In this study, we would like to introduce a case study of how Google Earth (GE) was used in a Computer Supported Collaborative Learning (CSCL) environment at a university setting.

\section{Geospatial Technology in Classrooms}

Geographic Information System (GIS) has become readily available and accessible than ever before. This technology offers a new representation of the geographical space. For example, Google Earth (GE) ${ }^{\circledR}$ is a geographic browser accessible on-line that has become by far most popular. GE is a geo-visualization technology, which allows us to see and interact with the virtual digital globe on the computer screens through the internet. Using GE may alter the way we perceive borders and "space". Unlike a paper-based atlas, using GE, the user can freely manipulate the aerial images by enlarging and minimizing the geographical images as if the user has the globe under control.

GE allows users to visually identify, gather, analyze and manage data on geospatial platform. GE is also a highly interactive platform. Using GE, users can add key words, texts and other identifying information to maps and aerial images of the globe. It also allows users to collaborate on the creation or enhancement of maps by adding and editing text, graphic, photos and videos [2]. In addition to such texts and graphics, users can also add 3D objects to the digital globe.

GE has been proven to be powerful tool in teaching and learning [2]-[4]. Google Earth can especially be effective in teaching spatial thinking [3], [4]. Spatial thinking, according to National Research Council is the knowledge, skills, and habits of mind to use spatial concepts, maps, and graphs and process of reasoning in order to organize and solve problems [5]. Spatial thinking is also "an amalgam of three concepts: concepts of space, tools of representation, and processes of reasoning" [5]. Bodzin \& Cirucci contend that the ability to use images and spatial technologies intellectually and critically will become an important requirement for global citizen and using GE effectively in learning and teaching may be a powerful way for fostering such skills [3]. Patterson also feels that GIS can contribute to unifying different discipline that focus on spatial trends, and using such technologies in classroom setting will help make spatial information more relevant to students [6].

The past research shows that Google Earth can be used in various educational contexts. GE has already been applied to education in many instances. Lamb \& Johnson point out that 
GE can take students to take virtual travel to far off places, and that it can be used to enrich teaching of different disciplines such as literature, fine art, social studies and science [2]. It can for example, bring literature alive through visualizing the settings of novels, and adding spatial representation and visualization in science curricular. Students can identify and analyze data on the GE and use the collected data for problem solving activities [2]. Many of the past instances that use GE in the classrooms integrate project based learning that often requires group work and collaboration.

\section{COLLABORATIVE LEARNING}

In this case study, we have integrated the use of GE in a Computer Supported Collaborative Learning (CSCL) environment. Collaborative learning creates a sense shared responsibility that comes with the knowledge building process. A sense of shared responsibility among participants for building and improving artifacts is crucial in successful collaborative project. Usually to accomplish a task, the students are asked to communicate with the group members. Also, students engaging in collaborative learning are expected to use their collaborative skills, such as interpersonal skills, inquiry skills and group management skills in order to successfully finish the project [7], [8]. In addition, past research shows that CSCL not only raises students`awareness on collaborative skills, but also raises ICT skills as well [8].

Such aspects of collaborative learning also apply in collaborative learning using GE. For example, students can browse GE to learn about geographical areas that are covered in global media news. In the process the students are asked to communicate with one another to gather information. In another case, students can upload 3D contents and images on GE based on the group research. In the process, the students are required to spatially recognize information, assess, reconstruct and distribute new artifact online.

\section{A. Curriculum Units}

In this research, we have used GE and Google Map ${ }^{\circledR}$ in a university curriculum. The course title was called "Social Design" which is a required course for the department of Media Sciences at Tokyo University of Technology. A total of 12 classes with approximately 30 students per class took the class for the Year 2015, Spring Semester. A total of 390 students took the course. The class consisted of total of 13.5 hours, over a period of three weeks. The purpose of the course was to learn about global and local social issues, research on a chosen topic in groups, think of a solution using design process, and to give group presentations. Since the educational goal of the curriculum was to find solutions for social issues, the students used open data on Google Earth, Google Map as well as maps available from Geospatial Information Authority of Japan. Fig. 1 is an example of how a student a student is using Google Map and Google Earth to research about a given topic, in this case about child labor.

\section{B. Curriculum Content and Digital Maps}

To research and analyze global issues, we asked the students to use GE in groups. They were also asked to incorporate images taken from GE for their final presentation product, which was a poster of a global issue. Global issue such as child labor and local issue such as revitalization of local community are some example of topic chosen by students. By using open data available on GE and Google Map, students were able to learn about the geographical boundaries and environment surrounding the chosen topic. Also, using functions on GE and Google Map, allows students to gain a broader perspective on a given topic without actually going to the place.

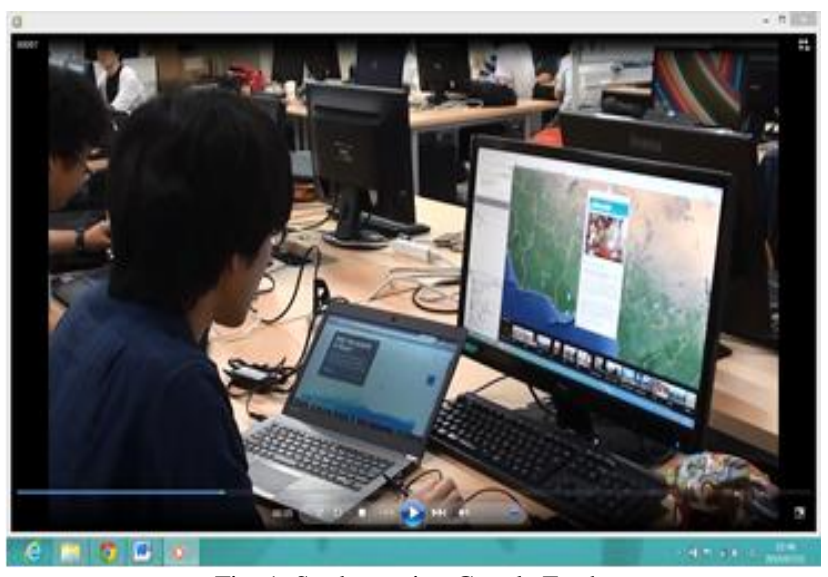

Fig. 1. Student using Google Earth.

Students also engaged in group discussion as the group decides how to create the final presentation poster. Fig. 2 is a sample digital poster created by the students. As the figure shows, the students integrated images taken from GE to create a digital poster using Power Point Slide. This poster was created by four students. The poster shows places in the world where World Wide Fund for Nature is active.

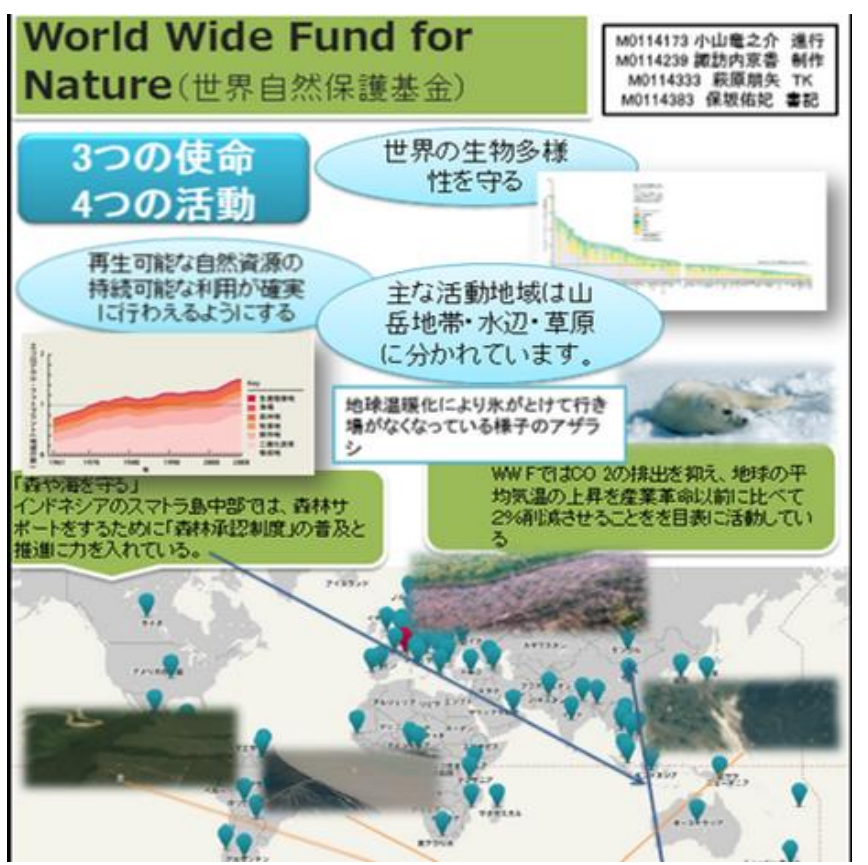

Fig. 2. Final student product.

\section{Collaborative Website}

In a CSCL environment, it is important for educators to create a learning environment that support ICT access and collaboration using GE or GIS. It is also important to provide 
an ICT environment that students can engage in both individual and group work. The course took place in a classroom where each student had access to a PC. In this case study, students used Microsoft Sharepoint ${ }^{\circledR}$ as a collaboration website. Students used Sharepoint to upload individual as well as group work. Using this system, a group of students could login to the system and simultaneously edit a same Excel Worksheet and Microsoft Powerpoint Slides as part of a group activity. Using this editing function, students created presentation files, maps and digital posters. Students worked in a group of four to five. Each group worked on a specific topic, research using GE and Google Maps, and co-created a final digital poster on-line and was uploaded to group workspace on Microsoft Sharepoint.

\section{QUESTIONNAIRE}

In order to investigate the students' perception on the interest in the topic of the course, use of digital maps, collaboration and the use of ICT, we have administered pre and post questionnaires. We administered a survey at the beginning and at the end of the semester to all the students enrolled in class to evaluate their perceptions on the curriculum. Same questions were asked to the same group of students before and after the semester.

TABLE I: PRE AND POST SURVEY RESULT
\begin{tabular}{|l|l|l|r|}
\hline QUESTIONS & $\begin{array}{l}\text { Post } \\
\text { survey } \\
\text { Mean }\end{array}$ & $\begin{array}{l}\text { Post } \\
\text { servey } \\
\text { SD }\end{array}$ & $\begin{array}{l}\text { *Pre and } \\
\text { Post survey } \\
\text { Difference }\end{array}$ \\
\hline Are you ineterested in global issues? & 1.96 & 0.67 & 0.17 \\
\hline Are you ineterested in social issues? & 2.09 & 0.62 & 0.22 \\
\hline $\begin{array}{l}\text { Are you interested in local issues? (i.e. revitalization } \\
\text { of local community) }\end{array}$ & 1.97 & 0.72 & 0.50 \\
\hline $\begin{array}{l}\text { Are you interested in contributing to social and local } \\
\text { issues through any actions including research and } \\
\text { learning? }\end{array}$ & 1.91 & 0.75 & 0.50 \\
\hline $\begin{array}{l}\text { By using digital maps are you able to imagine } \\
\text { geopraphical information surrounding social issues? }\end{array}$ & 1.74 & 0.82 & 0.24 \\
\hline $\begin{array}{l}\text { Do yo think groupwork in necessary to attain } \\
\text { objectives? }\end{array}$ & 2.58 & 0.63 & 0.20 \\
\hline $\begin{array}{l}\text { Do you think it is necessary to effectively use ICT } \\
\text { to attain objectives? }\end{array}$ & 2.50 & 0.62 & 0.18 \\
\hline 3.very much 2. fairly 1 not so much 0 not at all & & $\mathrm{N}=390$ \\
\hline
\end{tabular}

*Differences in average scorse between pre and post survey

The pre and post questionnaires consisted of four tiered likert-scale survey with answer choices as follows; very interested/fairly interested/interested/not interested at all. Each choice corresponded from 3 "very interested" 2 "fairly interested", 1 "not interested" and 0 "not interested at all", 3 being the highest and 0 being lowest. The questions asked were, how the students` interest changed before and after the course, how well maps were perceived related to the class topic, and how the students perception on collaboration and ICT changed before and after the course. Detailed question can be seen in Table I.

Table I shows the questions and the result for the pre and post questionnaires. The result shows that in all questions, the average scores increased in the post questionnaire. The result showed that the students interest in global and social issue raised after the course, also the student's awareness that collaboration is important in creating a common project raised as well as their awareness on the use of ICT. The average score on a question on the post survey which asked whether the students want to contribute by taking action, increased by 0.50 points compared to the pre questionnaire. This was the highest difference out of all the other questions. The average score of the question in the post survey on local issue also increased by 0.50 points, compared to the pre survey. Although the result of the question on the use of digital map was not as high as the other questions, overall, students felt they were able to imagine the geographical surroundings of social issues at hand.

\section{CONCLUSION}

Over a period of three week curriculum, in the first week the students used the Google Map and Google Earth to understand the social issues of the target area abroad, the second week`s activity was to make an original map based on a map of the Geospatial Information Authority of Japan using the image editing software. In the third week, the students designed a specific plan for actions and solutions using the map. The first week and the second week, the instructor facilitated and gave instructions on how to use and how to edit Google Earth and Google Map, in the third week, creation of the map and poster was left to the student. The students came up with a solution plan and edited the map to include a specific solution to the proposal.

The result of pre and post questionnaires showed that utilization digital maps and editing software in going through the lesson may have led to the increased understanding and interest in social issues. It may also be that the use of digital map and ICT mutually enhanced the course content and led to increased interests of the students on the topic covered in class. This also may have led to students` interest to take action for change. Past research on geospatial technology in the classroom looked at how analyzing spatial data and virtually visualizing space. Our study may indicate that such endeavors in the classroom may lead to change in awareness which leads to motivation for social action. However, we were not able to look deeply into literacy skills used and the process of making students' awareness change through visualization of space. Future research is needed to articulate information literacy skills that surrounds geospatial competency.

\section{REFERENCES}

[1] Science Council of Japan Regional Research Committee. (July 14, 2015). [Online]. Available: http://www.scj.go.jp/ja/info/kohyo/pdf/kohyo-22-t199-3.pdf

[2] A. Lamb and L. Johnson, "Virtual expeditions: Google Earth, GIS and geovisualization technologies in teaching and Learning," Teacher Librarian, vol. 37, no. 3, pp. 81-85, 2010.

[3] A. M. Bodzin and L. Cirucci, "A land-use-planning simulation using Google Earth,” Science Scope, vol. 32, no. 7, pp. 30-38, 2009. 
[4] A. M. Bodzin and L. Cirucci, "Integrating geospatial technologies to examine urban land use change: A design partnership," Journal of Geography, vol. 108, pp. 189-197, 2009.

[5] National Research Council, Learning to Think Spatially: GIS as a Support System in K-12 Education, Washington D.C.: National Academy Press, 2006.

[6] T. C. Patterson, "Google Earth as a (not just) geography education tool," Journal of Geography, vol. 106, pp. 145-152, 2007.

[7] M. Iinuma, T. Matsuhashi, T. Nakamura, and H. Chiyokura, "Collaborative learning using integrated groupware: A case study in a higher education setting," International Journal of Information and Education Technology, vol. 4, no. 4, pp. 351-355, 2014.

[8] M. Iinuma, T. Matsuhashi, T. Nakamura \& H. Chiyokura, "Student awareness change in computer supported collaborative learning (CSCL) environment," International Journal of Information and Education Technology, vol. 6, no. 6, pp. 448-452, 2016.

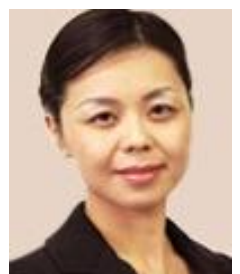

Mizuho linuma was born in Tokyo, Japan. She earned her doctoral degree in international educational development from Teachers College, Columbia University, New York, NY, USA in 2004. Her area of specialization is international educational development and educational technology.

Her past work experiences include as an adjunct professor at Queens College, City University of New York, a visiting lecturer at the Department of Environmental Information, Keio University. She is currently associate professor at Department of Media Science, Tokyo University of Technology located in Tokyo, Japan. Her recent works includes Learning and Teaching using Technology in Knowledge Society; New Literacy, Collaboration, Digital Content,( Springer-Verlag Singapur, 2016). Her current interest is in media and information literacy, international education, and collaborative learning.

Dr. Inuma is a member of the Japan Association for International Education, Japan Society for Educational Technology, among others. She has earned the 74th Conference Award from Information Processing Society of Japan.

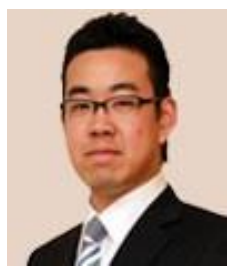

Takashi Matsuhashi was born in Ibaraki, Japan and earned his doctoral degree in Graduate School of Media and Governance, Keio University, Fujisawa, Kanagawa, Japan in 2012. His area of specialization is sports management and social innovation.

His past work experience include research associate at Graduate School of Media and Governance, Keio University, and a part-time lecturer at the Department of Policy Management. He is currently an assistant professor at the Department of Media Science, Tokyo University of Technology located in Tokyo, Japan.

Dr. Matsuhashi is a member of the Japan Society of Management for Physical Education and Sports, Japan Society of sports Industry, among others. He has earned the annual research Award from Japan Society of sports Industry in 2007 and Japan Society of Management for Physical Education and Sports in 2013

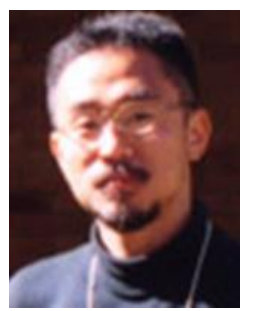

Tagiru Nakamura was born in Nagoya, Japan. He earned his master's degree from Graduate School of Media and Governance, Keio University, Fujisawa, Kanagawa. His area of specialization is in cognitive psychology and user experience design. His past work experience include an assistant professor at the Department of Media Science, Tokyo University of Technology. He is currently a lecturer at School of Media Science, Tokyo University of Technology located in Tokyo, Japan; and at Faculty of Environment and Information Studies, Keio University located in Kanagawa, Japan. His recent works include "The mechanism of sensing interestingness in metaphorical expressions". Professor Nakamura's current interest is in media and information literacy, user experience design, and technology for collaborative learning. He is a member of the Japanese Cognitive Science Society, the Japanese Psychological Association, among others.

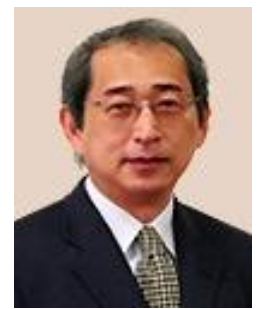

Hiroaki Chiyokura was born in Tokyo, Japan and earned his Ph.D from Tokyo University in 1984. His specialization is $3 \mathrm{D}$ computer graphics, and educational technology. His past work experiences include as a professor at the Department of Environmental Information, Keio University. He is also the founder of Lattice Technology Inc. Dr. Chiyokura is currently professor at the Department of Media Science, Tokyo University of Technology located in Tokyo, Japan. His works include Solid Modeling with Database (Addison-Wesley, 1988), 3DCAD: Principles and Applications. His current interest is in 3D documentation, social application of computer graphics, and e-learning. Dr. Chiyokura has earned the Intellectual Property Award 2006, Intellectual Property Center Keio University. 